\title{
CARACTERIZAÇÃO ANATÔMICA DAS MADEIRAS DE LIANAS DE SAPINDACEAE UTILIZADAS COMERCIALMENTE EM SÃO PAULO - SP
}

\author{
Neusa Tamaio ${ }^{1}$
}

(recebido: 23 de junho de 2010; aceito: 30 de junho de 2011)

\begin{abstract}
RESUMO: Este trabalho aborda o estudo anatômico das espécies de Sapindaceae que ocorrem em uma propriedade particular, fornecedora de fragmentos de lianas para a Associação para o Desenvolvimento Educação e Recuperação do Excepcional (Adere), um dos maiores produtores de peças de artesanato com lianas de São Paulo. A partir da identificação das espécies, procedeu-se a uma análise morfológica dos caules das lianas e à análise microscópica da secção transversal, com o objetivo de separar as espécies pelo lenho. Dos sete espécimes analisados, apenas um não possui variação cambial (Paullinia trigonia Vell.); o restante possui a variação cambial do tipo cilindro vascular composto. Os seis espécimes restantes pertencem ao gênero Serjania (Serjania caracasana (Jacq.) Willd, Serjania lethalis A. St.-Hill., Serjania laruotteana Cambess. e Serjania multiflora Cambess.), que podem ser distintos pela configuração da medula, do arranjo e da quantidade dos cilindros vasculares periféricos e de duas variáveis comprovadas estatisticamente: o diâmetro e a frequência dos elementos dos vasos. Apresenta-se uma chave para a identificação das espécies, ilustrações, além de comentários sobre o extrativismo praticado pela Adere.
\end{abstract}

Palavras-chave: Anatomia da madeira, marchetaria, Paullinia, Serjania.

\section{WOOD ANATOMY OF LIANAS OF SAPINDACEAE COMMERCIALLY USED IN SÃO PAULO - SP}

\begin{abstract}
We performed an anatomical survey of Sapindaceae species growing on the private property that supplies liana fragments to the Adere (Association for the Development and Recovery for the Intellectually Disabled), one of the major producer of art wood marquetry made from the lianas from Sao Paulo. Based on species identification, we carried out both morphological and microscopic analyses of the transversal section of lianas stems, with the aim of separating the species based on wood characters. Only one of the seven analyzed species had no cambial variant (Paullinia trigonia Vell.); the rest presented cambial variant of the compound vascular cylinder type. Also, the six remaining species belong to the following genera: Serjania (Serjania caracasana (Jacq.) Willd., Serjania lethalis A. St.-Hill., Serjania laruotteana Cambess., and Serjania multiflora Cambess.) These genera could be distinguished by pith configuration, arrangement and quantity of peripheral vascular cylinders, as well as two statistically significant quantitative features: the diameter and frequency of vessel elements. In this work, a key for species identification and illustrations are presented, in addition to comments about the extractivism carried out by Adere.
\end{abstract}

Key words: Wood anatomy, wood marquetry, Paullinia, Serjania.

\section{INTRODUÇÃO}

A madeira de espécies arbóreas constitui uma matéria-prima muito utilizada na produção artesanal brasileira. Recentemente, o artesanato com lianas e bambus vem se difundindo no Brasil.

Um dos maiores produtores formais de artesanato com lianas no Brasil éa Associação para o Desenvolvimento, Educação e Recuperação do Excepcional (Adere), uma entidade filantrópica, localizada na cidade de São Paulo, que, desde 1972, atende pessoas portadoras de deficiência intelectual (jovens, adultas e idosas) - os aprendizes - em oficinas de capacitação para o trabalho. Essa instituição produz objetos de artesanato confeccionados em bambus e lianas (também conhecidas como cipós). Neste trabalho, elegem-se as lianas como objeto de estudo.
As lianas são trepadeiras lenhosas que precisam de um suporte ou apoio para desenvolver-se e possuem contato com o solo, durante todo o seu ciclo vital (GENTRY, 1991; GERWING et al., 2006). A identificação anatômica do lenho de espécies arbóreas comercializadas já é uma ciência bem conhecida e praticada no Brasil, no entanto, essa prática ainda não é aplicada a esse grupo peculiar. Isso se deve, provavelmente, ao maior potencial econômico das plantas arbóreas, pelo fato de a anatomia do lenho de lianas ser uma ciência ainda incipiente e pelo uso comercial de lianas ser mais recente que as arbóreas.

As lianas podem possuir arranjos estruturais diferentes do hábito arbóreo, produzindo peças de decoração e utilitários únicos e singulares em sua beleza em razão dos seus diversos efeitos decorativos pelo arranjo anatômico do lenho, pela técnica da marchetaria.

\footnotetext{
${ }^{1}$ Bióloga, Doutora em Botânica - Diretoria de Pesquisa Científica - Instituto de Pesquisas Jardim Botânico do Rio de Janeiro - Rua Pacheco Leão, 915 - 22460-030 - Rio de Janeiro, RJ - neusa@jbrj.gov.br
}

Cerne, Lavras, v. 17, n. 4, p. 533-540, out./dez. 2011 
Nesse sentido, a família Sapindaceae é uma das mais apreciadas, pelos arranjos estruturais simétricos de seus caules, conhecidos, popularmente, como tipo "flor" e tipo "pé".

Esses arranjos, segundo Carlquist (2001), podem ser formados pela alteração na posição e quantidade de xilema e floema, aparecimento de novos câmbios e/ou atividade desigual deles. Alguns autores, como Esau (1977), Metcalfe e Chalk (1950, 1983) e Obaton (1960), classificam os caules com arranjos diferenciados como "caules anômalos". Carlquist (2001) sugere a substituição para o termo "variação cambial", pois, segundo o autor, o termo "anômalo" induz à impressão de ação desorganizada, o que não ocorre.

A presença de variações cambiais pode servir como instrumento para caracterizar família ou gênero (CABALLÉ, 1993): múltiplos câmbios em Gnetaceae e Menispermaceae, xilema interrompido em Bignoniaceae, caule achatado em Bauhinia e cilindro vascular composto em Serjania e Paullinia.

Em razão do crescente uso de amostras de Sapindaceae em objetos comercializados e pela ausência de padrões para comparações, propõe-se, neste artigo, um estudo morfológico dos caules das lianas de Sapindaceae. Pretende-se também fornecer subsídios para o reconhecimento das espécies por meio da macroscopia e da análise microscópica da secção transversal da madeira, constituindo-se, assim, uma primeira proposta de identificação de caules de lianas utilizadas comercialmente para o Brasil.

\section{MATERIAL E MÉTODOS}

O trabalho foi realizado no município de Itapecerica da Serra, em uma propriedade particular denominada "Sítio do Sr. Klein", que se trata de um remanescente de floresta ombrófila densa (Mata Atlântica) que se desenvolve sobre as encostas da Serra do Mar. A Serra do Mar é caracterizada por temperaturas elevadas, altas precipitações durante o ano, bem como pela predominância de árvores de grande a médio porte e abundância de lianas e epífitas (VELOSO et al., 1991).

Durante as coletas, procurou-se saber sobre o conhecimento empírico do extrativismo por parte da Adere, para entender se a exploração é ou não sustentável.

Foram realizadas coletas de material de Sapindaceae, no período de outubro de 2004 a fevereiro de 2006. A coleta do caule foi efetuada por meio de corte a 1 metro da base, para permitir a rebrota do indivíduo. Porções do lenho estão depositadas na Xiloteca do Instituto de Pesquisas Jardim Botânico do Rio de Janeiro (Tabela 1).

Tabela 1 - Espécimes analisados com número de coletor, $\mathrm{RBw}$ e tamanho.

Table 1 -Studied species with size, RBw and collection number.

\begin{tabular}{llcc}
\hline Espécie & $\begin{array}{c}\text { Número do } \\
\text { coletor }\end{array}$ & $\begin{array}{c}\text { Xiloteca } \\
(\mathrm{RBw})\end{array}$ & $\begin{array}{c}\text { Diâmetro } \\
(\mathrm{cm})\end{array}$ \\
\hline Paullinia trigonia & N. Tamaio 63 & 8995 & 2,7 \\
\multirow{2}{*}{ Serjania caracasana } & N. Tamaio 68 & 8996 & 3,6 \\
& N. Tamaio 89 & 8997 & 4,2 \\
Serjania laruotteana & N. Tamaio 72 & 8998 & 4,7 \\
Serjania letalhis & N. Tamaio 79 & 8999 & 5,8 \\
Serjania multiflora & N. Tamaio 82 & 9000 & 4,2 \\
\hline
\end{tabular}

$\mathrm{RBw}=$ Xiloteca do Instituto de Pesquisas Jardim Botânico do Rio de Janeiro

Processou-se a análise qualitativa de arranjo e quantidade de cilindros vasculares periféricos e confecção de ilustrações de cada espécie.

As amostras coletadas foram fixadas em FAA (ácido acético, formaldeído e etanol 70\%) (BERLYN; MIKSCHE, 1976) e estocadas em etanol $70 \%$. As amostras foram amolecidas por aquecimento em água, até estarem com a consistência adequada para o processamento, e emblocados em PEG (polietilenoglicol) 1500 (GERLACH, 1984). Foram obtidas secções histológicas do plano transversal, com cerca de 15 a $20 \mu \mathrm{m}$, em micrótomo de deslize, com navalha tipo $\mathrm{C}$ e com o auxílio de fita adesiva (KRUSE, 1977). As secções obtidas foram distendidas em PEG $30 \%$ e submetidas ao processo de dupla coloração, com safranina $1 \%$ e azul de astra 1\% (KRAUS; ARDUIN, 1997).

As análises anatômicas quantitativas foram realizadas para diâmetro tangencial de vaso, vasos por $\mathrm{mm}^{2}$ e raios por $\mathrm{mm}$, seguindo as recomendações da IAWA Committee (1989). O número de medições foi fixado em $n=30$. Esses dados quantitativos foram obtidos em microscópio de luz acoplado à câmera digital Cool Snap Pro e software Image pro Plus, versão 4, para análise de imagens. Para a análise anatômica qualitativa, foram seguidas as recomendações do IAWA Committee (1989) e as normas de procedimento em estudos da madeira de Coradin e Muñiz (1992).

Para a comparação entre as variâncias medidas no caule dos sete espécimes, aplicou-se, respectivamente, a Análise de Variância (ANOVA) e o teste de Tuckey para a comparação entre as médias. 
Para o reconhecimento do tipo de variação cambial existente nos objetos comercializados, foram analisadas 230 peças de artesanato fornecidas pela Adere. Os fragmentos pertencentes à família Sapindaceae foram observados a olho nu e a quantidade e o tipo de variação cambial foram registrados em uma planilha eletrônica.

A terminologia anatômica adotada para determinar o tipo de variação cambial existente nas espécies estudadas segue Tamaio e Angyalossy (2009): "cilindro vascular composto" para designar a variação cambial existente e "cilindro vascular periférico" para designar cada unidade vascular, assim como "caule do tipo composto" quando há necessidade de comparação com outros tipos de variações existentes em Sapindaceae.

\section{RESULTADOS E DISCUSSÃO}

\subsection{Características do extrativismo praticado pela Adere}

O corte e a exploração da vegetação da Mata Atlântica são proibidos pelo Código Florestal Estadual, porém, é possível o extrativismo controlado (DESMA, 2006).

A Adere busca a adequação ao meio ambiente no uso dos espécimes vegetais, por meio de um conhecimento empírico que consta em não eliminar a planta, incluindo o rodízio da área de exploração. Dessa forma, essa instituição criou um manejo informal da matéria-prima priorizando a coleta diversificada e não destrutiva das espécies.

As lianas possuem diferenças na capacidade de regeneração (VIDAL et al., 1997) e espécies relativamente raras podem ficar sob risco de extinção local (GERWING; VIDAL, 2002). Observou-se que 30 dias após o corte houve uma rebrota vigorosa de todos os espécimes da família Sapindaceae, indicando que a prática de exploração utilizada não causa dano permanente aos indivíduos coletados. No entanto, a análise do manejo utilizado deve ser avaliada quanto a sustentabilidade econômica e ambiental, tema não abordado nesse trabalho. É importante ressaltar que poucos estudos, tanto silviculturais quanto de manejo foram realizados com lianas com potencial econômico.

No Brasil, pode-se citar o trabalho de Lopes et al. (2008), que enfocam o plantio do cipó-cravo (Tynanthus fasciculatus Miers), uma liana com potencial econômico ou Coelho et al. (2007), abordando a infestação de cipós em áreas de manejo. O Desma (núcleo de estudos em desenvolvimento sustentável rural e mata atlântica) fornece algumas informações sobre o manejo e extrativismo de lianas. Esse grupo de estudos aponta o "cipó-timbó" como uma essência utilizada para artesanato no litoral Norte do Rio Grande do Sul e informa que se retiram as lianas com maior abundância na natureza com corte próximo à altura do joelho, mantendo a raiz no solo (DESMA, 2006).

\subsection{Características anatômicas}

As características macroscópicas, como a presença ou a ausência de variação cambial; quantidade e arranjo de cilindros vasculares periféricos e configuração da medula, foram observadas no plano transversal a olho nu e a estratificação dos raios foi observada no plano tangencial com o uso de lente de aumento de 10 vezes.

A madeira das lianas analisadas é similar, por meio da macroscopia, sendo que apenas Paullinia trigonia separa-se das demais pela ausência de variação cambial. Todas as espécies apresentam parênquima paratraqueal escasso, vasos solitários e múltiplos e raios não estratificados. Schenck (1893) relata quatro diferentes arranjos anatômicos em Sapindaceae: 1) corpo lenhoso composto (cilindro vascular composto); 2) corpo lenhoso dividido (cilindro vascular dividido); 3 ) corpo lenhoso cordado (cilindro vascular cordado); e 4) corpo lenhoso fissurado (cilindro vascular fissurado). Os dois primeiros tipos estão presentes apenas na família Sapindaceae.

As quatro espécies de Sapindaceae utilizadas pela Adere possuem em seus caules a variação cambial cilindro vascular composto. $\mathrm{O}$ caule tipo dividido assemelha-se ao tipo composto, com a diferença de que não existe um cilindro vascular central (SCHENCK, 1893). O tipo dividido não foi detectado em objetos comercializados pela Adere. Já, Araújo e Costa (2006) afirmam que o tipo dividido presente em Serjania corrugata é utilizado no artesanato, no entanto, os autores não apresentam informações adicionais, tampouco exemplificam o estado de ocorrência e/ou grupo produtor.

Nas Figuras 1 e 2 e na Tabela 2, observa-se que a presença de variação cambial, assim como a quantidade e disposição dos cilindros vasculares e a configuração da medula, são caracteres diagnósticos e formam três grupos.

O primeiro grupo está representado por Serjania caracasana (Figuras 1a-1b) e Serjania multiflora (Figuras 1c-1d) - ambas as espécies possuem a configuração em "flor" e têm comumente oito cilindros vasculares periféricos e medula em configuração octogonal (Figuras $2 a-2 b)$.

Cerne, Lavras, v. 17, n. 4, p. 533-540, out./dez. 2011 

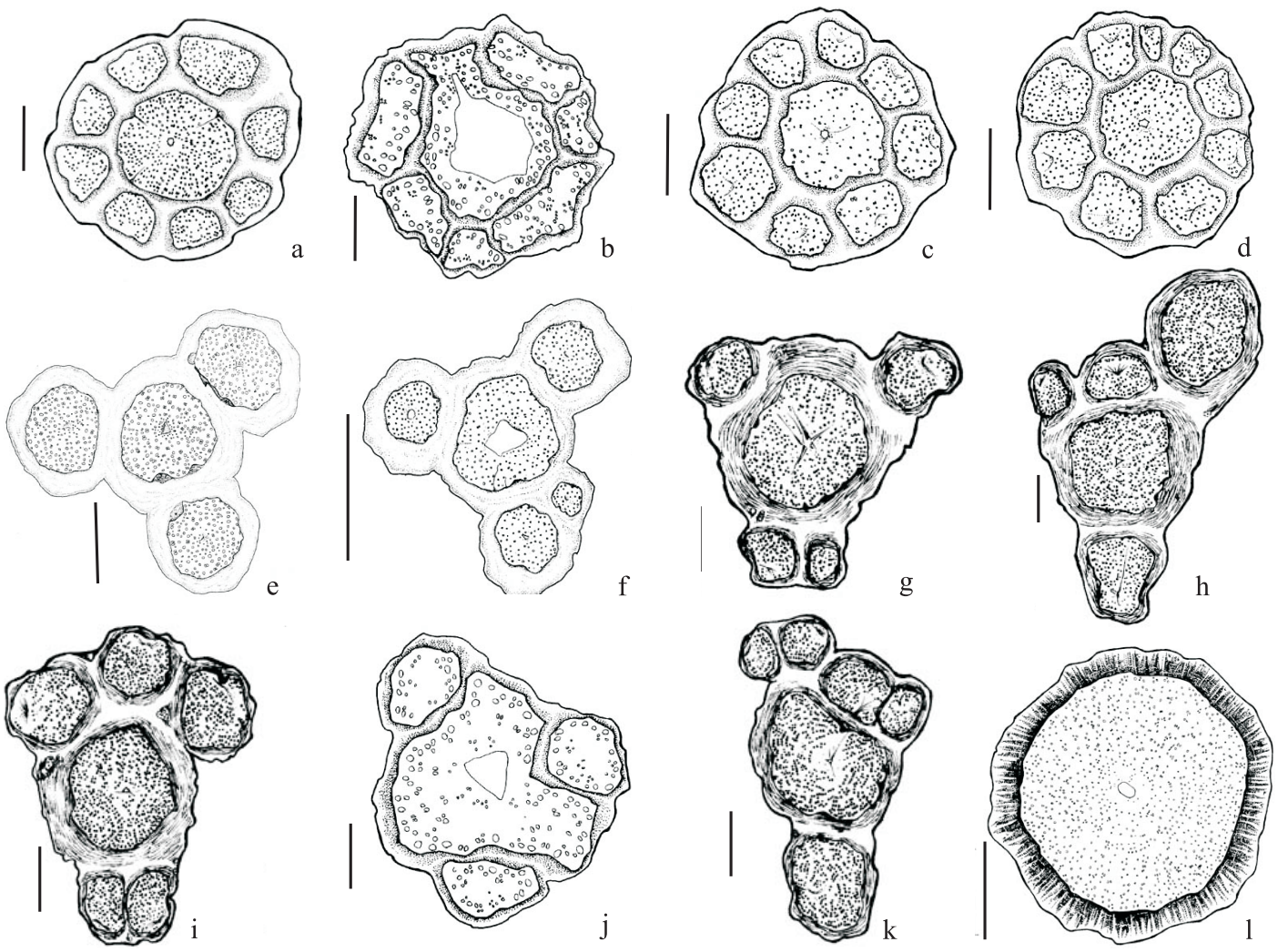

Figura 1 - Ilustrações da secção transversal dos caules das lianas utilizadas da família Sapindaceae comercializadas em São Paulo - SP. Observe a quantidade e disposição dos cilindros vasculares periféricos. - a-b. Serjania caracasana; c-d. Serjania multiflora; e-f. Serjania lethalis; g-k. Serjania laruotteana; 1 . Paullinia trigonia. Escala $=1 \mathrm{~mm}$.

Figure 1-Illustrations of the transversal section of the liana stems of Sapindaceae commercialized in São Paulo-SP. It is highlighted the quantity and disposition of the peripheral vascular cylinders. - a-b. Serjania caracasana; $c$-d. Serjania multiflora; e-f. Serjania lethalis; g-k. Serjania laruotteana; l. Paullinia trigonia. Bar $=1 \mathrm{~mm}$.
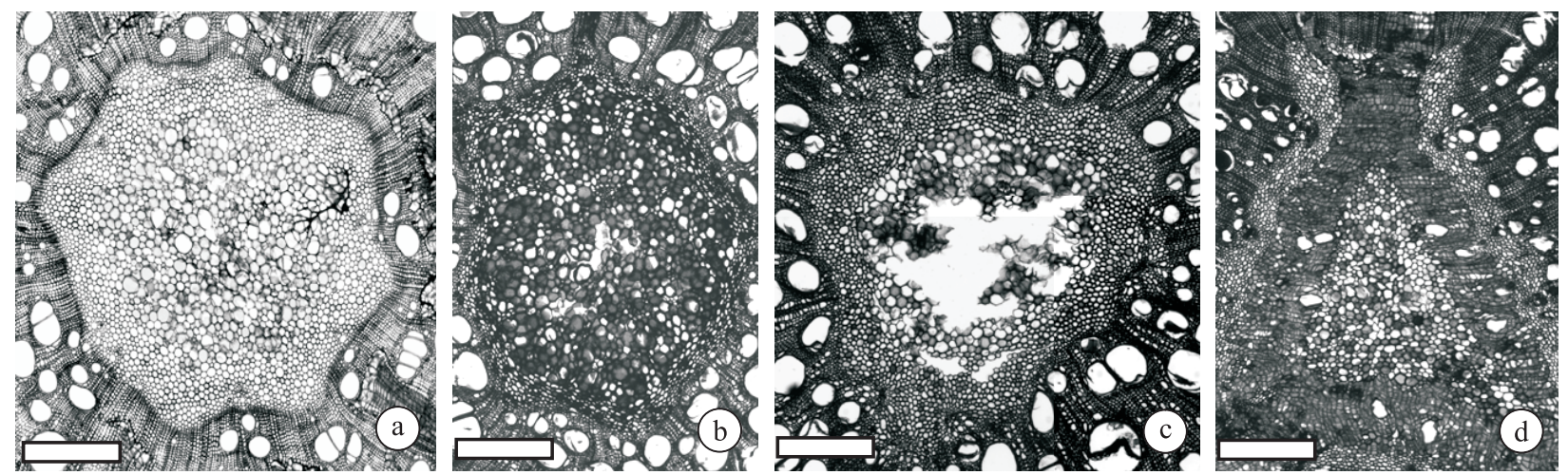

Figura 2 - Detalhe da medula dos caules de lianas utilizados da família Sapindaceae comercializadas em São Paulo - SP. Secção transversal. A. Serjania caracasana; b. Serjania multiflora; c. Serjania lethalis; d. Serjania laruotteana. Barra $=20 \mu \mathrm{m}$.

Figure 2 - Detail of the piths of used liana stems of Sapindaceae commercialized in São Paulo. Transversal section. a. Serjania caracasana; b. Serjania multiflora; c. Serjania lethalis; $d$. Serjania laruotteana. Bar $=20 \mu \mathrm{m}$.

Cerne, Lavras, v. 17, n. 4, p. 533-540, out./dez. 2011 
Tabela 2 - Quantidade, disposição, tipo e configuração da medula do caule tipo composto da família Sapindaceae comercializadas em São Paulo - SP.

Table 2 - Quantity, disposition, type and configuration of the pith of compound type of Sapindaceae commercialized in São Paulo - SP.

\begin{tabular}{lccc}
\hline Espécie & $\begin{array}{c}\text { Quantidade } \\
\text { de cilindros } \\
\text { vasculares }\end{array}$ & $\begin{array}{c}\text { Arranjo do } \\
\text { caule }\end{array}$ & $\begin{array}{c}\text { Configuração } \\
\text { da medula }\end{array}$ \\
\hline Serjania caracasana & $8-8-9$ & "flor" & octogonal \\
Serjania laruotteana & $4-4-6$ & $\begin{array}{c}\text { "pé" e "flor } \\
\text { (minoria)" }\end{array}$ & triangular \\
Serjania letalhis & $3-3-4$ & "triângulo" & triangular \\
Serjania multiflora & $8-8-9$ & "flor" & octogonal \\
\hline
\end{tabular}

O segundo grupo é representado por Serjania lethalis (Figuras 1e-1f) e Serjania laruotteana (Figuras 1g-1h-1i-1j-1k) - ambas com um número reduzido de cilindros vasculares quando comparadas com o grupo um e com medula em configuração triangular (Figuras 2c-2d). As características da morfologia do caule mostraram-se informativas. No entanto, com a intenção de separar esses táxons procedeu-se a análise microscópica da secção transversal do caule (Figuras 3a-e).

O terceiro grupo é representando apenas por Paullinia trigonia (Figura 11) - essa espécie não possui variação cambial (caule simples). Essa espécie também é citada como fonte de matéria-prima para o artesanato para confecção de cestos com a técnica do trançado (DESMA, 2006).

Serjania caracasana e Serjania laruotteana podem possuir uniformidade morfológica pelo tipo "flor", no entanto uma diferença pode ser observada. A configuração da medula é um caráter informativo e permite a distinção rápida entre essas duas espécies, pela análise macroscópica com o uso de lente de 10x.
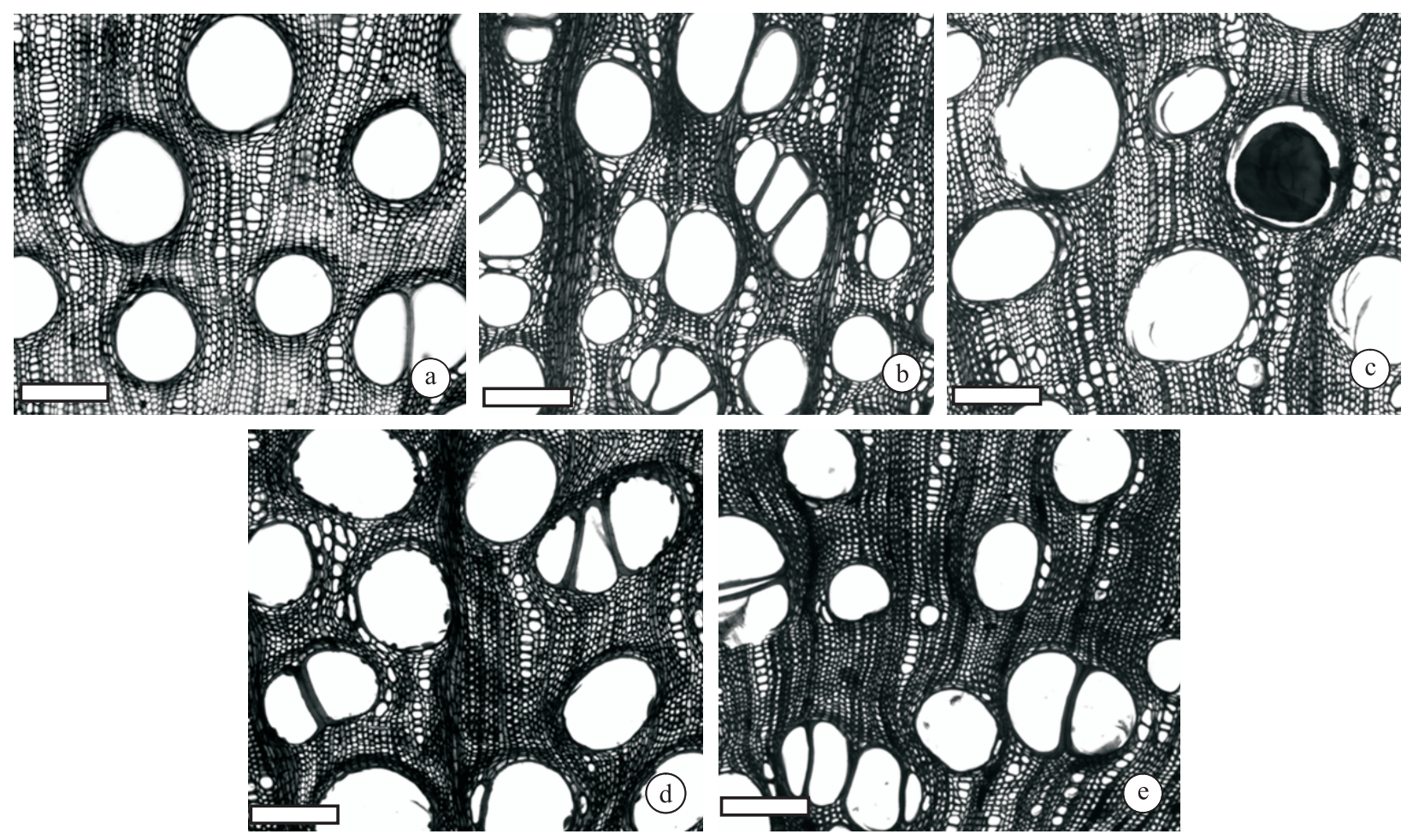

Figura 3 - Secção transversal do caule dos caules das lianas utilizadas da família Sapindaceae comercializadas em São Paulo - SP. Observe vasos de grandes e pequenos diâmetros. a. Serjania caracasana; b. Serjania multiflora; c. Serjania lethalis; d. Serjania laruotteana; e. Paullinia trigonia. Barra $=80 \mu \mathrm{m}$.

Figure 3 - Transversal section of the used liana stems of Sapindaceae commercialized in São Paulo. Observe vessels of large and small diameters. a. Serjania caracasana; $b$. Serjania multiflora; c. Serjania lethalis; $d$. Serjania laruotteana; e. Paullinia trigonia. Bar $=80 \mu m$. 
A estrutura básica da madeira das espécies analisadas é semelhante ao descrito por alguns autores para a família Sapindaceae (BAIZHONG et al., 1995; DÉTIENNE; JACQUET, 1983; KLAASSEN, 1999; METCALFE; CHALK, 1950; RECORD; HESS, 1943). As espécies apresentam as seguintes características em comum com os dados desses autores: porosidade difusa; parênquima axial paratraqueal escasso; placa de perfuração simples e cristais abundantes. A presença de vasos de dois diâmetros distintos e do parênquima axial e radial não lignificado é citada por Klaassen (1999) para as lianas de Sapindaceae e está associada com o hábito escalador.

O IAWA Committee (1989) recomenda que em espécies com dois diâmetros distintos de vasos sejam processadas as mensurações apenas dos vasos maiores. Klaassen (1999), que apresentam a anatomia da madeira para 104 gêneros e 348 espécies de Sapindaceae, sendo a maioria arbórea e poucas lianas, processou as mensurações dos vasos de maiores e também de menores diâmetros. No entanto, o autor utiliza os dados apenas para caracterizar as espécies, e em análises comparativas entre as arbóreas esse caráter não foi utilizado. Esse autor fornece os seguintes dados comparativos entre o gênero Paullinia e Serjania, respectivamente: $210-300 \mu \mathrm{m}$ e $90-340 \mu \mathrm{m}$, e para vasos menores relata o valor mínimo de $15 \mu \mathrm{m}$ para Paullinia. Cabe aqui relembrar que a presença de traqueídes é comum no lenho de Sapindaceae, portanto, a distinção entre uma traqueíde ou um vaso muito estreito é, praticamente, impossível de ser feita na secção transversal, sendo necessário que a mensuração seja realizada em material dissociado. Diante disso, as mensurações das espécies deste trabalho foram obtidas apenas dos vasos de maiores diâmetros $(>100 \mu \mathrm{m})$, seguindo as recomendações do IAWA Committee (1989).
O parênquima não lignificado é definido pelo IAWA Committee (1989) como um tecido que ocorre geralmente em faixas largas, restrito a poucas famílias de espécies arbóreas, como Tiliaceae e Urticaceae. Esse tecido é geralmente descrito para famílias de espécies escaladoras (CARLQUIST, 2001), plantas suculentas como Crassulaceae e plantas que habitam regiões áridas, como Brassicaceae e Cactaceae (METCALFE; CHALK, 1950).

O parênquima axial e radial não lignificado é um caráter informativo para as espécies estudadas, destacandose Serjania caracasana como a espécie que possui a maior abundância.

$\mathrm{Na}$ Tabela 3, reúnem-se os principais dados microscópicos obtidos com potencial diagnóstico. Acevedo-Rodrígues (1993) afirma que a anatomia da madeira para as lianas de Sapindaceae é pouco informativa, sendo que o arranjo estrutural do caule é mais importante para esse grupo. Os resultados aqui apresentados não corroboram essa afirmação. Qualitativamente, o lenho das espécies analisadas é homogêneo, no entanto, foram encontradas diferenças significativas para as variáveis: diâmetro tangencial dos vasos e vasos por $\mathrm{mm}^{2}$. Com relação ao diâmetro tangencial dos vasos, Paullinia trigonia (Figura 3e) apresentou as menores médias $(165 \mu \mathrm{m})$, enquanto Serjania multiflora (Figura $3 \mathrm{~b})$ apresentou as maiores médias $(266 \mu \mathrm{m})$. Já, para a variável vasos por $\mathrm{mm}^{2}$, Serjania caracasana (Figura 3a) tem as menores médias (6), enquanto Paullinia trigonia e Serjania multiflora possuem as maiores médias (23 e 22, respectivamente).

Os caracteres macroscópicos e microscópicos da secção transversal permitem a confecção de uma chave de identificação para a separação das espécies.

Tabela 3 - Dados quantitativos do xilema das lianas da família Sapindaceae comercializadas em São Paulo - SP.

Table 3 - Quantitative data for the xylem of the lianas of Sapindaceae commercialized in São Paulo - SP.

\begin{tabular}{lcccccc}
\hline \multirow{2}{*}{ Variáveis } & \multicolumn{2}{c}{$\mathrm{X}$} & & ANOVA \\
\cline { 2 - 7 } & $\begin{array}{c}\text { Paullinia } \\
\text { trigonia }\end{array}$ & $\begin{array}{c}\text { Serjania } \\
\text { caracasana }\end{array}$ & $\begin{array}{c}\text { Serjania } \\
\text { laruotteana }\end{array}$ & $\begin{array}{c}\text { Serjania } \\
\text { letalhis }\end{array}$ & $\begin{array}{c}\text { Serjania } \\
\text { multiflora }\end{array}$ & Valor de $\mathrm{p}$ \\
\hline $\begin{array}{l}\text { Diâmetro tangencial } \\
\text { dos vasos }\end{array}$ & $165 \mathrm{a}$ & $198 \mathrm{~b}$ & $210 \mathrm{~b}$ & $202 \mathrm{~b}$ & $266 \mathrm{c}$ & $0,0000^{*}$ \\
Vasos $\mathrm{mm}^{2}$ & $23 \mathrm{a}$ & $6 \mathrm{c}$ & $10 \mathrm{~b}$ & $11 \mathrm{~b}$ & $22 \mathrm{a}$ & $0,0006^{*}$ \\
Raios $\mathrm{mm}$ & $9 \mathrm{a}$ & $8 \mathrm{a}$ & $9 \mathrm{a}$ & $7 \mathrm{a}$ & $7 \mathrm{a}$ & $0,5348 \mathrm{~ns}$ \\
\hline
\end{tabular}

Médias seguidas de letras iguais na mesma coluna não diferem significativamente entre si, a nível de 5\% (Análise de Variância seguida de teste Tukey-Kramer).

Medida $=$ micrometro $(\mu \mathrm{m}), \mathrm{X}=$ média.

Cerne, Lavras, v. 17, n. 4, p. 533-540, out./dez. 2011 
3.3 Chave para as espécies de Sapindaceae utilizadas pela Adere, em São Paulo - SP

1. Caule sem variação estrutural (caule simples). ..Paullinia trigonia

1'. Caule com variação cambial (caule tipo composto).

2. Presença de 8-9 cilindros vasculares periféricos; medula em configuração losangular; caule em configuração de "flor". Presença de muito ou pouco parênquima não lignificado.

3. Presença de grande quantidade de parênquima não lignificado. Baixa porosidade...........S. caracasana 3'. Presença de pouca quantidade de parênquima não lignificado. Alta porosidade.................S. multiflora

2'. Presença de 3-6 cilindros vasculares periféricos; medula em configuração triangular; caule em configuração de "pé" ou "triângulo". Presença de pouco parênquima não lignificado.

4. Presença de 4-7 cilindros vasculares periféricos. Caule com formato de "pé". Vasos com diâmetro médio $<250 \mu \mathrm{m}$. S. laruotteana 4'. Presença de 3-4 cilindros vasculares periféricos, mas comumente 3. Caule com formato de "triângulo". Vasos com diâmetro médio $>250 \mu \mathrm{m}$ S. lethalis

\section{CONCLUSÕES}

Estudos comparativos enfocando a anatomia da madeira de lianas podem contribuir com os órgãos responsáveis pela autorização e fiscalização do uso dessas lianas utilizadas comercialmente. Esse trabalho demonstra que a análise macroscópica juntamente com alguns caracteres do padrão estrutural anatômico de caules de lianas da família Sapindaceae é promissora para a identificação de materiais comercializados. No entanto, recomendam-se novas pesquisas abordando um maior número de táxons.

\section{AGRADECIMENTOS}

Agradecemos à Adere, especialmente aos aprendizes; à Dra. Genise Somner, a identificação do material; à artista Fernanda Sartori, a confecção das ilustrações, aos pareceristas, as excelentes sugestões e à Petrobras, o auxílio financeiro.

\section{REFERÊNCIAS}

ACEVEDO-RODRÍGUEZ, P. Systematics of Serjania (Sapindaceae) part I: a revision of Serjania Sec. Platycoccus.
Memoirs of the New York Botanical Garden, London, v. 67, p. 1-93, 1993.

ARAÚJO, G. U. C.; COSTA, C. G. Cambial variant in the stem of Serjania corrugata (Sapindaceae). IAWA Journal, Utrecht, v. 27, p. 269-280, 2006.

BAIZHONG, L.; WELLE, B. J. H. ter; KLAASSEN, R. K. W. M. Wood anatomy of trees and shrubs from China: VII., sapindaceae. IAWA Journal, Utrecht, v. 16, p. 200-214, 1995.

BERLYN, G. P.; MIKSCHE, J. P. Botanical microtechnique and cytochemistry. Ames: State University, 1976. 326 p.

CABALLÉ, G. Liana structure, function and selection: a comparative study of xylem cylinders of tropical Forest species in Africa and America. Botanical Journal of the Linnean Society, London, v. 113, p. 41-60, 1993.

CARLQUIST, S. Comparative wood anatomy. 2. ed. Berlin: Springer Verlag, 2001. 436 p.

COELHO, D. J. S.; SOUZA, A. L.; SOARES, C. P. B.; LEITE, H. G. Alteração estrutural de áreas de florestas exploradas convencionalmente em planos de manejo, nos domínios de floresta atlântica, Minas Gerais, Brasil. Revista Árvore, Viçosa, v. 31, n. 5, p. 867-877, set./out. 2007.

CORADIN, V. T. R.; MUNIZ, G. I. de. Normas e procedimentos em estudos de anatomia da madeira: angiospermae II-gimnospermae. Brasília: IBAMA; DIRPED; LPF, 1992. 17 p. (Série técnica, 15).

DESMA. Núcleo de Estudos em Desenvolvimento Rural e Mata Atlântica. Uso de plantas aquáticas e cipós para confecção de artesanato. Maquine: Fundação Estadual de Pesquisa Agropecuária, 2006. 10 p.

DÉTIENNE, P.; JACQUET, P. Atlas d'identification des bois de l'amazonie et des régions voisines. Montpellier: Centre Technique Forestier Tropical, 1983. 279 p.

ESAU, K. Anatomy of seed plants. 2. ed. New York: J. Wiley, 1977. $550 \mathrm{p}$.

GENTRY, A. H. The distribution and evolution of climbing plants. In: PUTZ, F. E.; BULLOCK, S.; MONNEY, H. A. (Ed.). The biology of vines. Cambridge: Cambridge University, 1991. chap. 1.

Cerne, Lavras, v. 17, n. 4, p. 533-540, out./dez. 2011 
GERLACH, D. Botanische Microtechnik. Stuttgart: G. Thieme, 1984. $311 \mathrm{p}$.

GERWING, J.; SCHNITZER, S. A.; BURNHAM, R. J.; BONGERS, F.; CHAVE, J.; DESALT, S. J.; EWANGO, C. E. N.; FOSTER, R.; KENFACK, D.; MARTÍNEZ-RAMOS, M.; PARREN, M.; PARTHASARATHY, N.; PÉREZ-SALICRUP, D. R.; PUTZ, F. E.; THOMAS, D. W. A standard protocol for liana censuses. Biotropica, Lawrence, v. 38, p. 256-261, 2006.

GERWING, J.; VIDAL, E. Changes in liana abundance and species diversity eight years after liana cutting and logging in an eastern Amazonian forest. Conservation Biology, Boston, v. 16, p. 544-548, 2002.

IAWA COMMITTEE. International association of wood anatomists: list of microscopic features for hardwood identification. IAWA Bulletin, Leiden, v. 10, p. 220-332, 1989.

KLAASSEN, R. Wood anatomy of the Sapindaceae. IAWA Journal, Utrecht, v. 20, n. 2, p. 150-200, 1999. Supplement.

KRAUS, E. J.; ARDUIN, M. Manual básico de métodos em morfologia vegetal. Rio de Janeiro: Edur, 1997. 198 p.

KRUSE, J. Mikrotechnologische und biologische Untersuchungen an Rindenplatten. 1977. Dissertation (Master in Fachbereich Biologie) - Universität Hamburg, Hamburg, 1977.

LOPES, M. M. M.; CARVALHO-OKANO, R. M.; SOUZA, A. L.; PAIVA, H. N. Crescimento de mudas de cipó-cravo (Tynanthus fasciculatus Miers), uma liana com potencial

Cerne, Lavras, v. 17, n. 4, p. 533-540, out./dez. 2011 medicinal. Revista Árvore, Viçosa, v. 32, n. 2, p. 211-216, mar./abr. 2008.

METCALFE, C. R.; CHALK, L. Anatomy of the dicotyledons: leaves, stem and wood in relation to taxonomy with notes on economic uses. Oxford: Clarendon, 1950. v. 1, 724 p.

METCALFE, C. R.; CHALK, L. Anatomy of the

dicotyledons: wood structure and conclusion of the general introduction. Oxford: Clarendon, 1983. v. 2, 213 p.

OBATON, M. Les lianes ligneuses à structure anomale des forêts denses d'Afrique Ocidentale. Annals of the Science Natural Botany, Warwick, v. 12, n. 1, p. 1-220, 1960.

RECORD, S. J.; HESS, R. W. Timbers of the new world. New Have: Yale University, 1943. 640 p.

SCHENCK, H. Beiträge zur biologie und anatomie der Lianen. Jena: V. G. Fischer, 1893. 342 p.

TAMAIO, N.; ANGYALOSSY, A. Variação cambial em Serjania caracasana (Sapindaceae): enfoque na adequação terminológica. Rodriguesia, Rio de Janeiro, v. 60, p. 651-666, 2009 .

VELOSO, H. P.; RESENDE FILHO, A. L. R. R.; LIMA, J. C. A. Classificação da vegetação brasileira, adaptada a um sistema universal. Rio de Janeiro: IBGE, 1991. 123 p.

VIDAL, E.; BARRETO, P.; JOHNS, J.; GERWING, J.; UHL, C. Vine management for reduced-impacts logging in Eastern Amazon. Forest Ecology and Management, Amsterdam, v. 98, p. 105-114, 1997. 